\title{
Conexões transnacionais entre as mulheres de direita \\ Brasil, Chile e Estados Unidos*
}

\author{
Transnational connections \\ among right-wing women \\ Brazil, Chile, and the United States
}

MARGARET POWER**
Department of Humanities
Illinois Institute of Technology
Chicago, Illinois Chicago, Illinois
USA

RESUMO Este artigo discute a importância transnacional dos movimentos de mulheres contra João Goulart, no Brasil, e contra Salvador Allende, no Chile, e o impacto que tiveram sobre as mulheres conservadoras dos Estados Unidos. Para tanto, examina a ampla cobertura que a mídia, nos Estados Unidos, deu aos movimentos dessas mulheres, assim como as visitas que as mulheres anti-Goulart fizeram aos Estados Unidos após o golpe militar brasileiro de 1964. Ele explora vários casos em que mulheres conservadoras brasileiras e chilenas partilharam suas experiências e suas vitórias políticas com as mulheres da América do Norte, que, por sua vez, foram inspiradas por elas. $O$ artigo desafia a literatura acerca das mulheres de direita nos Estados Unidos, que tem ignorado o impacto que as muIheres conservadoras do Brasil ou do Chile tiveram sobre os movimentos desse país.

\footnotetext{
* Artigo recebido em: 12/09/2013. Autora convidada

**Contato: power@iit.edu

Tradução de Clara Furtado Lins.
} 
Palavras-chave mulheres de direita, transnacionalismo, Brasil, Estados Unidos

ABSTRACT This article establishes the transnational importance that the women's movements against João Goulart in Brazil and Salvador Allende in Chile had on conservative women in the United States. To do so, it examines the extensive coverage that media in the United States gave to these women's movements as well as the visits that anti-Goulart women made to the United States following the Brazilian military's 1964 overthrow of his government. It explores multiple instances in which conservative Brazilian and Chilean women shared their political experiences and victories with North American women, who were in turn inspired by them. It challenges the literature on right-wing women in the United States, which has largely ignored the impact that conservative women in Brazil or Chile have had on movements in that country.

Keywords right-wing women, transnationalism, Brazil, United States

\section{Introdução}

O Brasil oferece um excelente exemplo de como as mulheres podem salvar uma nação da dominação comunista. São principalmente as mulheres que merecem o crédito da derrubada do comunismo de Allende, no Chile. Tudo o que as mulheres brasileiras e chilenas podem fazer, as mulheres americanas positivas podem fazer. ${ }^{1}$

Foi pouco antes de eu ir para o Chile, em 1993, para realizar pesquisas para a minha dissertação sobre as mulheres de direita neste país, ${ }^{2}$ que li, pela primeira vez, estas palavras escritas por Phyllis Schlafly, chefe do Eagle Forum e ativista conservadora, que liderou a bem-sucedida campanha para anular a Emenda dos Direitos Igualitários da Constituição dos EUA, em 1982. Intrigada com a referência de Schlafly às próprias mulheres que eu planejava estudar, entrei em contato com o Eagle Forum para ver se eles poderiam sugerir pessoas com quem eu poderia entrar em contato enquanto estivesse no Chile. Mandaram-me o nome de um padre norte-americano que vivia no país e havia sido muito favorável ao regime militar liderado pelo general Augusto Pinochet, que governara o Chile de 1973 a 1990. Na época, eu supunha que as conexões existentes entre os ativistas de direita

SCHLAFLY, Phyllis. The power of the positive woman. New York: Jove Publications, 1987, p.221-223.

POWER, Margaret. Right-wing women in Chile: feminine power and the struggle against Allende, 1964-1973.

University Park: Penn State University Press, 2002. 
nos Estados Unidos e no Chile se davam, principalmente, de maneira unidirecional: viajando do Norte para o Sul. No entanto, eu compreendi, então, que a relação entre as mulheres de direita no Brasil, no Chile e nos Estados Unidos era multidirecional, fluindo do Sul para o Norte, do Sul para o Sul e do Norte para o Sul. Este artigo analisa o fluxo transnacional de informações e ideias sobre o anticomunismo e a construção de movimentos a partir de um ângulo diferente - aquele das mulheres conservadoras no Brasil e no Chile, em direção às mulheres de direita nos Estados Unidos - para obter uma perspectiva nova e, espero, mais completa sobre a relação que se estabeleceu entre as mulheres de direita nos Estados Unidos e na América Latina. $^{3}$

A literatura sobre as mulheres de direita nos Estados Unidos tem ignorado largamente as conexões entre estas e as mulheres de direita latino-americanas. Em vez disso, as analisa somente no contexto nacional dos EUA, isolado do mundo global do qual fazem parte. Por exemplo, o estudo de Lisa McGirr, sobre a direita no sul da Califórnia, não considera a possível influência que as mulheres de ideologia anticomunista do Brasil, ou do Chile, poderiam ter tido sobre as norte-americanas, que thes eram contemporâneas. ${ }^{4}$ Da mesma forma, o estudo de Donald Critchlow sobre Phyllis Schlafly não menciona que esta se inspirou nos sucessos que as mulheres conservadoras alcançaram no Brasil e no Chile, nem que ela tornou-os modelos para as mulheres nos Estados Unidos. ${ }^{5}$ Marjorie J. Spruill também não considera o impacto que as mulheres brasileiras e chilenas conservadoras podem ter tido nas ativistas socialmente conservadoras norte-americanas. ${ }^{6}$

Este artigo explora vários casos em que mulheres conservadoras brasileiras e chilenas partilharam suas experiências e vitórias políticas com as mulheres da América do Norte que, por sua vez, foram inspiradas por elas. No final da década de 1950 e início da década de 1960, no auge da Guerra Fria, a ala direita dos EUA trabalhou para superar as derrotas eleitorais, nacional e localmente, e construir um movimento que poderia tanto desafiar o que eles definiram como a "Ameaça Vermelha", quanto fazer retornar os

3 Este artigo se centra nas contribuições que as mulheres brasileiras e chilenas fizeram ao desenvolvimento do pensamento e do ativismo anticomunista nos Estados Unidos e não tem como objetivo negar ou minimizar o papel central que vários agente oficiais e instituições norte-americanos tiveram na fomentação do anticomunismo nas Américas.

4 MCGIRR, Lisa. Suburban warriors: the origins of the New American Right. Princeton: Princeton University Press, 2001. Da mesma forma, o excelente livro de Kim Phillips-Fein, sobre o movimento conservador nos Estados Unidos, focaliza nas contribuições feitas por empresários para o seu crescimento e não nos laços que eles possuíam com qualquer força não localizada nos EUA. Ver PHILLIPS-FEIN, Kim. Invisible hands: the making of the conservative movement from the New Deal to Reagan. New York: W. W. Norton, 2009.

5 CRITCHLOW, Donald T. Phyllis Schlafly and grassroots conservatism: a women's crusade. Princeton/Oxford: Princeton University Press, 2005.

6 SPRUILL, Marjorie J. Gender and american's right turn. In: SCHULMAN, Bruce J.; ZELIZER, Julian E. (eds.). Rightward bound: making America conservative in the 1970s. Cambridge: Harvard University Press, 2008. 
conservadores ao poder político. ${ }^{7}$ Lisa McGirr analisa a bem sucedida organização dessas forças conservadoras ao nível de base, bem como suas ligações e seu impacto sobre a direita, no nível nacional, nos EUA. Assim como suas congêneres de outras partes dos Estados Unidos, elas eram "obcecadas pelo comunismo" e assustadas com o que acreditavam ser a "expansão do comunismo desde a Segunda Guerra Mundial". A vitória da Revolução Cubana, de 1959, a apenas cerca de 90 milhas da fronteira dos Estados Unidos, combinada com o triunfo das lutas de libertação nacional pró-soviéticas, na Ásia e na África, aumentaram seus medos e intensificaram seu compromisso de organizar-se contra os comunistas. ${ }^{8}$

É neste contexto que as forças conservadoras nos Estados Unidos elogiaram o sucesso das mulheres anticomunistas do Brasil e do Chile. Como era gratificante contrariar a vitória das forças pró-socialistas em Cuba e no Vietnã, alardeando o triunfo das mulheres anticomunistas no Brasil e no Chile! Essas mulheres, muitas das quais eram donas de casa, e não os políticos, foram de importância simbólica e prática para as mulheres conservadoras nos Estados Unidos. Em primeiro lugar, elas representavam a capacidade da mulher "comum" em organizar um movimento bem sucedido e ofereciam às mulheres dos Estados Unidos um modelo em que elas poderiam se inspirar para realizar seu objetivo de derrotar o comunismo, tanto nacionalmente, como internacionalmente. Em segundo lugar, uma vez que estas mulheres tinham sido bem sucedidas em derrotar os presidentes eleitos, João Goulart (1961-1964), no Brasil, e Salvador Allende (1970-1973), no Chile, elas ofereciam um farol de esperança num momento em que as forças conservadoras se sentiam "desprovidas de poder e influência". 9

Embora as mulheres chilenas, brasileiras e norte-americanas, que são o assunto deste artigo, tenham vivido em nações distintas, localizadas a quilômetros de distância uma das outras, elas compartilhavam um ódio e um medo comum em relação ao comunismo. Elas também compartilhavam a crença de que as mulheres tinham o poder e a responsabilidade de articular e agir de acordo com sua oposição ao que elas percebiam ser o comunismo, seja na forma do reformismo de João Goulart, no Brasil, do socialismo de Salvador Allende, no Chile, ou do liberalismo e da esquerda crescentes, nos Estados Unidos. Essas mulheres eram guerreiras devotas da Guerra Fria; elas se viam como defensoras da nação, da democracia, do sistema de livre mercado, da religião e da liberdade, o que os regimes militares, que depois governaram no Chile e no Brasil, se referiam como "a

\footnotetext{
7 A esmagadora vitória do democrata Lyndon Johnson sobre o republicano Barry Goldwater levou ao movimento conservador moderno. Ver: EDSALL, Thomas Byrne; EDSALL, Mary D. Chain reaction: the impact of race, rights, and taxes on American politics. New York: W.W. Norton, 1992; SCHNEIDER, Gregory. The conservative century: from reaction to revolution. Boulder: Rowman and Littlefield, 2009.

8 MCGIRR, Lisa. Suburban warriors, p.69-70.

9 MCGIRR, Lisa. Suburban warriors, p.66.
} 
civilização ocidental cristã", contra os ataques lançados a eles pelos (assim chamados) comunistas totalitários ateus.

\section{Mulheres brasileiras conservadoras contra João Goulart}

Em 1961, João Goulart tornou-se presidente do Brasil e tentou implementar programas que poderiam melhorar a situação econômica de grande número de brasileiros, que viviam em condições de pobreza. Infelizmente, sua posição em favor do desenvolvimento brasileiro provocou a ira de empresas norte-americanas e do governo dos EUA, que o rotulou de comunista. No Brasil, as mulheres conservadoras mobilizaram-se contra ele logo depois que assumiu a presidência. ${ }^{10}$ Elas se opuseram ao seu governo porque alegavam (erroneamente) que ele ameaçava "impor um sistema totalitário no Brasil". ${ }^{11}$ Elas também afirmavam que Goulart era um ateu, que ameaçava a Igreja Católica e a liberdade delas de praticar a religião. Essas mulheres escreveram cartas para protestar contra suas políticas, falaram no rádio para explicar sua aversão aos seus programas e organizaram passeatas para gerar um movimento de massa anti-Goulart. Depois que Goulart criticou algumas dessas mulheres conservadoras por usarem a religião para promover seus próprios fins políticos, as forças de oposição convocaram uma Marcha da Família com Deus pela Liberdade. Em resposta, aproximadamente 500.000 pessoas se manifestaram contra Goulart, em São Paulo, em 19 de março de 1964, cerca de duas semanas antes que os militares depusessem Goulart da presidência, em 31 de março. ${ }^{12}$ Apesar da tomada ilegal do poder por parte dos militares e do uso de métodos repressivos, as mulheres conservadoras louvaram o golpe militar e seu próprio papel para o fim do governo democraticamente eleito de João Goulart.

Durante a década de 1960 e o início da de 1970, as mulheres chilenas anticomunistas olharam para as mulheres brasileiras em busca de inspiração para sua própria luta contra Salvador Allende. As mulheres brasileiras

10 Alguns excelentes estudos foram feitos acerca dessas mulheres e sua participação no movimento de deposição de Goulart. Ver SIMÕES, Solange de Deus. Deus, pátria e família: as mulheres no golpe de 1964. Petrópolis: Vozes, 1985; STARLING, Heloísa Maria Murgel. Os senhores das gerais: os novos inconfidentes e o golpe militar de 1964. Rio de Janeiro: Vozes, 1986; ASSIS, Denise. Mulheres: por Deus e pela família. In: _. Propaganda e cinema a serviço do golpe. Rio de Janeiro: FAPERJ/MAUAD, 2001; CORDEIRO, Janaina Martin. Femininas e formidáveis. Revista Genero, v.8, p.175-208, 2009; CORDEIRO, Janaina Martins. A nação que se salvou a si mesma: entre memória e história, a campanha da mulher pela democracia (1962-1974). Niterói: Universidade Federal Fluminense, 2008 (História, Dissertação de mestrado); PRESSOT, Aline Alves. As marchas da família com Deus pela liberdade e o golpe de 1964. Rio de Janeiro: Universidade Federal do Rio de Janeiro, 2004 (História, Dissertação de mestrado); SESTINI, Pérola. A "mulher brasileira" em ação: motivações e imperativos para o golpe militar de 1964. São Paulo: Universidade de São Paulo, 2008 (História, Dissertação de mestrado).

11 "Manifesto". O Diário de Pernambuco, 08/03/1964.

1219 de março é o dia de São José, o santo padroeiro da família. DULLES, John F. W. Unrest in Brazil: political-military crisis 1955-1964. Austin: University of Texas Press, 1970, p. 275. Para uma discussão sobre as forças que se alinharam para produzir o golpe, ver FICO, Carlos. Além do golpe: versões e controvérsias sobre 1964 e Ditadura Militar. Rio de Janeiro: Record, 2004; DREIFUSS, René Armand. 1964: a conquista do estado. Petrópolis: Vozes, 1987. Sobre o papel dos EUA, ver BLUM, William. Killing hope: U.S. military and CIA interventions since World War II. Monroe: Common Courage Press, 1995. 
ficaram felizes em compartilhar suas histórias com elas. ${ }^{13}$ Allende havia sido, democraticamente, eleito presidente, em setembro de 1970, com um programa que previa mudanças de longo alcance para a economia chilena, incluindo a nacionalização das empresas multinacionais norte-americanas, a redistribuição de terras dos grandes proprietários e uma redistribuição de riqueza para os pobres, por meio do aumento dos salários e de serviços sociais. Assim como no Brasil, as mulheres chilenas anticomunistas trabalharam assiduamente e com ousadia para organizar outras mulheres com o intuito de se oporem ao governo e encorajar as Forças Armadas a derrubar o presidente. Como suas congêneres no Brasil, elas empregaram uma variedade de táticas, que iam desde a panfletagem a anúncios pagos nos jornais, a discursos no rádio, a protestos e marchas, com o intuito de gerar sentimentos contra Allende e cultivar um clima favorável à tomada de poder pelos militares. Os militares depuseram Allende a 11 de setembro de 1973, declararam o estado de sítio e instituíram medidas brutais, como a tortura, o assassinato e o exílio, para garantir seu domínio. Durante seu governo de dezessete anos, as Forças Armadas louvaram repetidamente essas mulheres e promoveram-nas a heroínas que salvaram a nação do comunismo. ${ }^{14}$

\section{A cobertura midiática dos EUA em relação às mulheres conser- vadoras brasileiras}

Como é que essas mulheres souberam uma das outras? Uma fonte importante foi a mídia impressa nos Estados Unidos, que incluía desde o The New York Times, passando pelo Reader's Digest, a Time e o Newsweek, até os jornais de pequenas cidades publicados por todos os Estados Unidos, que levaram as notícias dessas mulheres a uma variedade de locais. Quando primeiro realizei a pesquisa sobre essas mulheres, eu me debrucei sobre os grandes jornais norte americanos, como The New York Times, The Washington Post, The Los Angeles Times e Reader's Digest. Posteriormente, percebi que o meu foco restrito a esses jornais privilegiava o setor urbano e bem-educado da população das metrópoles dos EUA e ignorava as pequenas cidades, vilas, aldeias e áreas rurais, onde vivia um grande número de americanos e que tinha sido território fértil para a organização e a ideologia de extrema direita. Quando olhei para fora das grandes cidades, descobri que muitos jornais de cidades pequenas relataram o papel conservador de mulheres brasileiras e chilenas na construção dos movimentos anticomunistas em seus países. As matérias afirmavam que as mulheres haviam sido fundamentais para a derrota do "comunismo" no Brasil e no Chile e,

13 SIMÕES, Solange de Deus. Deus, pátria e família, p.134.

14 Para uma discussão mais ampla acerca dessas mulheres, ver POWER, Margaret. Right-wing women in Chile. 
ou deixavam implícito, ou diziam diretamente, que as mulheres nos Estados Unidos deviam seguir seus exemplos.

John Chamberlain começou sua carreira como repórter do New York Times e depois aproximou-se da direita, passando a admirar os expoentes ideológicos do movimento conservador, como Friedrich von Hayek, Ludwig von Mises e William F. Buckley. ${ }^{15}$ Ele escreveu resenhas de livros na National Review, ${ }^{16}$ de Buckley, e foi colunista sindicalizado ao King Features Syndicate, que era de propriedade de William Randolph Hearst. ${ }^{17}$ Ele escreveu inúmeros artigos, que foram distribuídos por todo o Estados Unidos, exaltando as ações das mulheres brasileiras, que se opunham a Goulart, e das mulheres chilenas, que se opunham a Allende. Em um artigo publicado no The Light (San Antonio, Texas), Chamberlain escreveu que, quando os brasileiros souberam que o governo Goulart tinha dado instruções para "as embaixadas e os consulados darem vistos aos comunistas que queriam ir ao Rio de Janeiro para um congresso de esquerda", aqueles que se opunham à chegada destes lançaram um protesto. "No negócio de perseguir os visitantes de esquerda, de cidade em cidade, as mulheres brasileiras tiveram um papel dominante". ${ }^{18}$ (grifo nosso)

A Pacific Stars and Stripes, "publicação autorizada das Forças Armadas dos Estados Unidos", também publicou um dos artigos de Chamberlain sobre o Brasil. Intitulado Brasileiros contrariam plano de Castro, nele Chamberlain vangloriou-se de que "os generais brasileiros que derrubaram o governo esquerdista de João Goulart tem [sic] feito mais, pode-se razoavelmente supor, para barrar a marcha do comunismo, do que qualquer outra coisa que aconteceu no mundo ocidental, desde que o presidente Harry Truman decidiu fincar o pé na Coréia". Assim como em seus outros artigos, Chamberlain elogiou o papel das mulheres para o fim do governo Goulart. Referindo-se à ação mencionada acima, Chamberlain escreveu:

As mulheres da cidade de Belo Horizonte lideraram uma manifestação que expulsou os visitantes de esquerda de volta à própria capital de Goulart, Brasília, em busca de espaço de discussão. Diante disso, as mulheres de Brasília, por sua vez, formaram o que era a antítese direta de um comitê de boas vindas. 0 desempenho dessas mulheres lembrou as mulheres fortes, que em todo o mundo são chamadas de Amazonas, devido ao grande rio do Brasil. ${ }^{19}$

Outro jornalista, Edgar Miller, trabalhou para a Associated Press no Brasil entre os anos 1960 e 1970, e escreveu o que as mulheres brasileiras

15 BRIDGES, Linda; COYNE, John R. Strictly right: William F. Buckley and the american conservative movement. Hoboken: John Wiley and Sons, 2007, p.26-27.

16 BRIDGES, Linda; COYNE, John R. Strictly right, p.40.

17 Ver The birth of king features syndicate. Disponível em: < http://kingfeatures.com/about-us/king-features-history/> Acesso em: 12/09/2013

18 CHAMBERLAIN, John. Brazilian Nutcrackers. The Light, 10/04/1964.

19 CHAMBERLAIN, John. Brazilians Upset Castro's Applecart. Pacific Stars and Stripes, 15/04/1964. 
fizeram para incentivar a "revolução". ${ }^{20}$ Em um artigo, ele narrou a ascensão do movimento feminino anti-Goulart e concluiu que "o golpe culminante das mulheres [contra Goulart] foi a marcha de protesto em massa, em São Paulo, que mobilizou cerca de 500 mil pessoas, logo após o comício de Goulart ter atraído 200 mil". ${ }^{21}$

Em um artigo publicado em vários jornais, John Chamberlain ligou o Brasil, o Chile e o papel que as mulheres desempenharam na oposição a Goulart e a Allende. Sua mensagem era que as mulheres brasileiras derrotaram Goulart e as mulheres chilenas deveriam fazer o mesmo com Allende. Em 1964, o governo dos EUA estava muito preocupado com o fato de que Salvador Allende, um membro do Partido Socialista, derrotaria o Democrata Cristão, Eduardo Frei, que Washington apoiava na eleição presidencial que se aproximava. No artigo A esperança chilena liderada pelas mulheres, Chamberlain escreveu que "as mulheres brasileiras bloquearam a incipiente tomada de poder pelos comunistas" e afirmou que a mudança política que se insurgia contra o "comunismo", que ele acreditava estar acontecendo no Chile nos dias que antecederam à votação, aconteceu porque "as mulheres assumiram a liderança para forçá-la". ${ }^{2}$

No entanto, a publicação que atingiu o maior número de pessoas nos EUA e que foi claramente calculada para ter o maior impacto sobre o povo norte-americano foi a edição de novembro de 1964 da Reader's Digest. ${ }^{23}$ Em circulação, ela ficava atrás apenas da TV Guide, e a Reader's Digest educava os americanos sobre o mundo, seu lugar nele e sua relação com ele. Como Joanne Sharp observa em seu estudo da Reader's Digest, a revista:

Ilustra porque os leitores devem se preocupar com as políticas globais e qual a relevância que os eventos distantes podem ter em suas vidas. Inevitavelmente, a Digest explica porque a vigilância e a ação são necessárias aos leitores individu-

20 MILLER, Edgar. Personal communication, 16/11/2009

21 MILLER, Edgar. Brazilian women spurred revolution. Alton Telegraph, 21/06/1964. Alton, Illinois, era a cidade natal de Phyllis Schlafly. Como no artigo de John Chamberlain, variações desses artigos apareceram em diferentes jornais nos Estados Unidos. Ver, por exemplo, os artigos nos seguintes jornais: The Cedar Rapids, 28/06/1964; Garden City Telegram, Kansas, 08/07/1964; The Progress (Clearfield, Curwensville, Phillipsburg, PA), 11/07/1964; Port Angeles Evening News, Washington, 06/08/1964; Brazilian Ladies Helped for Freedom. The Victoria Advocate, Texas, 05/07/1964; Brazilian Women Spurred Revolution. The Ada Evening News, Oklahoma, 19/06/1964.

22 CHAMBERLAIN, John. Women may save Chile from commies. The Chronicle-Telegram, Ohio, 21/08/1964; it was also published on that same date as Chilean hope led by women. The Oneonta Daily Star, New York; Chilean women. New Castle News, PA, 21/08/1964; The women may yet save Chile. The Daily Courier, Connellsville; Voting in Chile. The Daily Messenger, Canandaigua; Chilean politics and OAS sanctions. The Cumberland News, Maryland; Chilean left defeat seen, The Gazette, Emporia; These days. The Columbus Daily Telegram, Nebraska, 25/08/1964.

23 A audiência de leitores dessa história ia além da Reader's Digest. Os jornais se apropriaram dessa história e referiram-se a ela como parte de seus artigos sobre as mulheres brasileiras, multiplicando, assim, o impacto da questão. Ver, por exemplo, Brazilian women sacrifice golden rings for freedom, under the heading The Woman's Page. Beckley Post-Herald, West Virginia, 24/11/1964 or "Another opportunity to defuse the reds: pray our leaders use it", which was an article written by the Cardinal Mindszenty Foundation, in The Sunday News and Tribune, Jefferson City, 15/11/1964 
ais, a fim de que qualquer ameaça aos Estados Unidos possa ser interrompida antes de se efetivar e desafiar diretamente a eles e suas famílias. ${ }^{24}$

Claramente convencido de que o papel desempenhado pelos brasileiros na derrubada de Goulart era importante para as pessoas nos Estados Unidos, Clarence W. Hall, um editor sênior da Reader's Digest, escreveu A Nação que se salvou a si mesma. Hall aplaude as ações dos "amadores preparados para combate, trabalhando contra os revolucionários comunistas endurecidos" e elogia as mulheres "femininas, mas formidáveis", especialmente as "donas de casa, [que] se lançaram à luta e, mais do que qualquer outra força, (...) alertaram o país". ${ }^{25}$ Ele também escreve que a história de sucesso desses brasileiros anticomunistas oferece "um modelo para todas as nações igualmente ameaçadas", uma vez que a derrubada de Goulart "é prova revigorante de que o comunismo pode ser interrompido, quando as pessoas estão suficientemente mobilizadas e determinadas". ${ }^{26}$

O artigo destaca Amélia Bastos, uma das líderes da Campanha da Mulher pela Democracia (CAMDE), um dos grupos de mulheres anticomunistas que surgiu no Rio de Janeiro para se opor a Goulart. Hall a descreve como uma "centelha e a força impulsora da revolta das mulheres no Rio de Janeiro". Ela era "um pequeno pacote de 90 pounds de pura energia feminina". Em 1962, Bastos "decidiu, de repente, que a política tornou-se demasiado importante para ser deixada inteiramente aos homens". Ela pediu a suas amigas, umas "30 donas de casa prontas para a batalha", para agir. Percebendo que trinta mulheres não eram suficientes, "Dona Amélia e seu grupo congregaram (...) 500". Elas, então, lançaram seu protesto contra uma nomeação que Goulart queria fazer de "seu primeiro ministro tingido de vermelho". "O protesto não impediu a nomeação; mas estabeleceu o poder das mulheres em influenciar a opinião pública". ${ }^{27}$

Hall via Amélia Bastos como um símbolo que encarnava o ímpeto anticomunista, que ele admirava e esperava que as mulheres nos Estados Unidos iriam imitar. Ele claramente tinha a intenção de que a mensagem do artigo - que "cidadãos interessados" poderiam derrotar o comunismo com sucesso - fosse lida e compreendida pelas pessoas nos Estados Unidos e ao redor do mundo. Um trecho no final do artigo, intitulado Como você pode usar este artigo para melhor efeito, incentivava os leitores a se engajarem ativamente no compartilhamento da "informação útil" que tinham acabado de ler, já que esta "animadora" história "merece a mais ampla divulgação. A mensagem é esta: com determinação e planejamento inteligente, uma

24 SHARP, Joanne P. Condensing the Cold War: Reader's Digest and American identity. Minneapolis/London: University of Minnesota Press, 2000, p.X.

25 HALL, Clarence W. The country that saved itself. Reader's Digest, p.137, p.143I, 11/1964

26 HALL, Clarence W. The country that saved itself, p.137.

27 HALL, Clarence W. The country that saved itself, p.143-144. 
cidadania despertada pode livrar-se até mesmo de uma ameaça comunista profundamente enraizada". A Digest, em seguida, enumera três coisas que os leitores podiam fazer: "enviar este artigo para um amigo, obter reimpressões para enviar ao exterior e levar cópias com eles quando viajassem ao exterior". ${ }^{28}$

\section{Mulheres brasileiras levam sua mensagem para as mulheres dos Estados Unidos}

Os norte-americanos também ouviram as mulheres brasileiras anticomunistas de forma direta. Em outubro e novembro de 1964, o Departamento de Educação e Intercâmbio Cultural, do Departamento de Estado, dos EUA, deu Leader Grants (Bolsas de Liderança), para uma "viagem de estudo de dois meses nos Estados Unidos", a quatorze brasileiras, que eram "líderes de movimentos políticos voluntários anticomunistas de mulheres". ${ }^{29}$ As mulheres vieram para "observar as eleições nos Estados Unidos, no dia 03 de novembro". ${ }^{30}$ (Não posso deixar de observar a ironia nessas mulheres que vêm para aprender sobre as eleições nos Estados Unidos, pouco depois de terem agitado, com sucesso, em favor da derrubada militar da democracia brasileira!) As mulheres participaram de um seminário, de 19 a 30 de outubro, no Brookings Institute, um reduto do pensamento liberal em Washington, D.C., que foi organizado pelo Overseas Education Fund (OEF), da Liga de Mulheres Eleitoras. ${ }^{31}$ Quando estavam em Washington, D.C., elas participaram da $32^{\mathrm{a}}$ Convenção Nacional de Mulheres Católicas, de 11 a 14 de novembro, organizada pelo Conselho Nacional de Mulheres Católicas anticomunistas, em que compareceram cerca de três mil mulheres. ${ }^{32}$ As mulheres foram, então, para o Wellesley College (onde as Secretárias de Estado, Madeleine Albright e Hilary Clinton, posteriormente, graduaram-se) e, de lá, viajaram para Ohio, Tennessee, Arizona e para a Costa Oeste. A viagem terminou na cidade de Nova lorque. ${ }^{33}$

28 HALL, Clarence W. The country that saved itself, p.159. A versão portuguesa do artigo, A Nação que se salvou a si mesma, foi publicada na Seleções do Reader's Digest, no Brasil, em novembro de 1964. A versão em espanhol foi publicado no México, em dezembro de 1964, para a distribuição pela América Latina. Edição especial também foi publicada na Austrália, no Canadá (tanto em inglês, quanto em francês), na Índia, na Itália, no Japão, em Portugal, na África do Sul e no Reino Unido. Ann DiCesare, Head Librarian, Editorial Research Library, Reader's Digest Association, Personal communication, 26 September 2006. A Seleções do Reader's Digest não era uma parte desinteressada, ela contribuía com o IPES, assim como vários outros bancos brasileiros, associações e companhias financeiras. DREIFUSS, René Armand. 1964, p.638.

29 ZANDT, Lydia Van. Brazilian women fight communism. Christian Science Monitor, 27/11/1964.

30 HORNADAY, Mary. Brazil's women hit their stride. Christian Science Monitor, 20/11/1964.

31 ZANDT, Lydia van. South Americas take a long look. Christian Science Monitor, 13/10/1964

32 SHELTON, Elizabeth. They're wedded to the freedom of Brazil. Washington Post, 11/11/1964, Section E1 (For and about Women); Catholic women attend meeting in wakeman. Sandusky Register, 13/10/1964; LCBA told of national get-together. Leader Times, Sandusky, 15/01/1965. For a discussion of the National Council of Catholic Women, see WEAVER, Mary Jo. New catholic women: a contemporary challenge to traditional religious authority. Bloomington/ Indianapolis: Indiana University Press, 1995, p.119-123.

33 ZANDT, Lydia Van. Brazilian women fight communism. 
Três das "donas de casa brasileiras" deram uma conferência de imprensa, patrocinada pela Reader's Digest, em Washington, D.C. A jornalista Elizabeth Shelton participou da conferência de imprensa e sua história sobre essas mulheres foi publicada em jornais de todo os Estados Unidos. As mulheres brasileiras queriam dizer às pessoas nos Estados Unidos "como elas ajudaram a impedir uma tomada comunista de seu país por meio de organização de marchas e distribuição de propaganda". ${ }^{34}$

A história de Shelton também enfatizava que as mulheres anticomunistas tinham doado suas alianças de ouro (em troca de alianças de ferro) e outras joias para levantar três milhões de dólares para ajudar "a causa da democracia no Brasil, depois que os comunistas tinham sido expulsos do país, levando a maior parte do tesouro nacional com eles". Um artigo impressionante, veiculado na Página da Mulher, do Beckley Post-Herald (West Virginia), observou que "Num Brasil moderno, o desejo das mulheres combina com seus anéis de casamento. Ambos são feitos de ferro". ${ }^{35}$ Um artigo muito semelhante apareceu no Daily Northwestern, só que este destacava Amélia Bastos, a líder da CAMDE. De acordo com esse artigo, Bastos:

Deu a alguns americanos engajados em ações semelhantes às suas, alianças de ferro para serem usadas como anéis de amizade, símbolo da luta pela liberdade no Brasil. Se você ver tal anel em uma mulher americana, você saberá que ela foi reconhecida como alguém continuamente consciente da necessidade de preservar a liberdade através da ação. ${ }^{36}$

As mulheres brasileiras tinham uma mensagem que elas queriam comunicar ao seu público nos Estados Unidos: as mulheres eram importantes na luta contra o comunismo. Para ilustrar este argumento, elas levaram "fotografias com elas que mostravam como mais de 1.000.000 de mulheres se concentraram, no Rio e em São Paulo, na última primavera, para exigir e agradecer pela libertação de seu país de uma tomada comunista iminente". ${ }^{37}$ Amélia Bastos, líder da delegação, queria que as mulheres nos Estados Unidos soubessem que "as mulheres são ainda melhores para se infiltrarem do que os comunistas". Sua mensagem para as mulheres nos Estados Unidos era "que, embora as mulheres brasileiras se sintam 'na frente' do mundo livre, elas sabem que apenas venceram uma batalha contra os comunistas. 'Nós, as mulheres do Brasil, descobrimos o nosso poder. Agora iremos trabalhar para preservar a democracia que ajudamos a salvar', ela declarou". Quando Bastos estava em Nova York, ela "foi ho-

\footnotetext{
34 SHELTON, Elizabeth. They're wedded to the freedom of Brazil.

35 Brazilian women sacrifice golden rings for freedom. Beckley Post-Herald, West Virginia, 04/11/1964

36 Wills, rings of iron. Daily Northwestern, Osh Kosh, 23/11/1964.

37 HORNADAY, Mary. Brazil's women hit their stride. Christian Science Monitor, 20/11/1964.
} 
menageada pela Reader's Digest, que, neste mês, contou a história [dela] em um artigo: O país que se salvou a si mesmo". ${ }^{38}$

As mulheres brasileiras não foram as únicas que relataram seus esforços bem sucedidos para derrotar "o comunismo". A Sra. George Colman ajudou a fundar a primeira Associação Cristã das Mulheres Jovens, no Rio de Janeiro. Ela e seu marido, o Dr. Colman, que trabalhava para o Departamento de Estado dos EUA no Rio de Janeiro, moraram no Brasil por 25 anos. 0 Dr. Colman, mais tarde, serviu como cônsul americano em Punta Arenas, no Chile, antes de ambos voltarem para os Estados Unidos. A Sra. Colman havia ensinado na Greeley Highschool, no Colorado. Ao mesmo tempo em que as mulheres brasileiras estavam viajando pelos Estados Unidos, ela se dirigiu ao Clube Feminino Greeley, junto com seu marido, para falar sobre o tema do programa Velho e Novo Brasil, nossos vizinhos do Sul. O tema que abordou foi "As mulheres brasileiras e o papel que tiveram na revolução de $1^{\circ}$ de Abril contra o comunismo". ${ }^{39}$

\section{Mulheres chilenas: símbolos da luta anticomunista}

Durante o resto da década de 1960, as referências às mulheres conservadoras brasileiras ou chilenas apareceram, na melhor das hipóteses, esporadicamente, na mídia dos EUA. No entanto, com a eleição de Salvador Allende em 1970, as mulheres chilenas conservadoras, mais uma vez, chamaram a atenção da mídia dos EUA e, como veremos a seguir, de anticomunistas, como Phyllis Schlafly. Durante grande parte do primeiro ano do governo Allende, duas histórias dominaram a cobertura da mídia dos EUA sobre as mulheres chilenas: a sua relutância em usar hot pants (seus maridos reprovavam!) e a sua obsessão com Simplemente María, uma novela que "90 por cento de todas as mulheres chilenas [com uma TV] assistiam" todas as noites. ${ }^{40}$ No entanto, em $1^{\circ}$ de dezembro de 1971 , apenas uma semana depois que o último artigo foi publicado nos jornais dos Estados Unidos, milhares de mulheres chilenas marcharam através de Santiago, acenando com panelas vazias e cantando slogans anti-Allende. Embora tenham sido veiculados alguns artigos nos meios de comunicação norte americanos que retratavam a relação de Allende com as mulheres sob uma luz positiva, a imagem de milhares de mulheres desfilando pelas ruas de Santiago garantiu a atenção da mídia dos EUA e foi publicada em jornais e revistas de todo o país. Colocando as mulheres no centro do palco da política chilena (esqueça as hot pants e a novela), a cobertura do New York

38 HORNADAY, Mary. Brazil's women hit their stride.

39 Greeley woman's club slates international day. Greeley Tribune, 06/11/1964.

40 Ver, por exemplo, Soap opera brings calm to nightlife in Chile. Anniston Star, Alabama, 25/11/1971; MARTíNEZ, Luis. Hot pants rejected. The Lima News, 10/08/1971. 
Times do protesto definiu os rumos com sua primeira frase sensacionalista: "O bater rítmico das panelas e frigideiras vazias por milhares de mulheres chilenas, na semana passada, teve o som de tambores de guerra". Ela caracterizou a marcha como "a mais violenta desde que o presidente Salvador Allende Gossens assumiu o cargo, há 13 meses". ${ }^{41}$

Outros jornais também focaram no papel das mulheres, na resposta violenta à sua ação por parte dos partidários de Allende e no espírito das mulheres que realizaram a marcha. Os artigos tinham títulos como Esquerdistas atacam mulheres chilenas durante o protesto, que se baseava em ideias sexistas de feminilidade e de masculinidade para retratar, simultaneamente, as mulheres como vítimas heroicas, e os apoiadores (masculinos) do governo Allende como brutos sem cavalheirismo. ${ }^{42} \mathrm{Um}$ artigo de duas páginas, na revista Time, sobre a marcha ecoava este mesmo tema ${ }^{43} \mathrm{~A}$ imagem das mulheres chilenas protestando contra o governo, acenando com frigideiras e panelas, e esquerdistas atacando-as, tornou-se recorrente na mídia dos EUA. Em outubro de 1972, durante o auge da greve dos caminhoneiros contra o governo, os jornais americanos novamente traziam imagens de exuberantes mulheres chilenas anti-Allende carregando a bandeira do Chile, segurando no alto panelas vazias, sorrindo e com aparência triunfante. ${ }^{44}$ Vários jornal repetiram o título Esquerdistas atacam mulheres chilenas, em artigos subsequentes, apenas no caso do leitor ter perdido a sugestão anterior de que homens chilenos de esquerda haviam atacado mulheres chilenas conservadores. ${ }^{45}$

Depois que os militares, com o apoio dos Estados Unidos, derrubaram o governo Allende, em 11 de setembro de 1973, uma série de artigos foi publicada na mídia dos EUA, exaltando o papel das mulheres em sua expulsão. O artigo de David Belnap, no Los Angeles Times, alardeava que os "grupos organizados de mulheres que se opunham a Allende (...) desempenharam um papel decisivo nos eventos que levaram à queda de Allende". ${ }^{46}$ Outros artigos informavam os planos da ditadura militar (que nunca chegaram a acontecer) de construir um monumento "para as mulheres do Chile, por seu papel, há um ano, na derrubada do governo de esquerda do presidente Salvador Allende". Estes artigos, que caracterizavam as mulheres como "corajosas", contribuíram para a disseminação da consciência de que as mulheres anticomunistas desempenharam um papel importante na

41 ONIS, Juan de. The ominous pounding of pots. New York Times, 05/12/1971.

42 Para um exemplo, ver The Lawton Constitution, Oklahoma, 02/12/ 1971.

43 Chile: empty pots and yankee plots. Time, 13/12/1971.

44 Ver Chilean women demonstrate against Allende. The Daily Republic, South Dakota, 11/11/1972.

45 YOLEN, Steven H. Leftists attack chilean women. Bucks County Courier Times, Pennsylvania, 04/09/1973. Este artigo apareceu apenas uma semana antes do golpe militar, após o qual os militares não apenas atacaram as mulheres, mas assassinaram-nas.

46 Corn pie plot, Chile's women: power behind Allende's fall. Los Angeles Times, 31/01/1974. Este artigo do sindicado foi reimpresso nos jornais através dos Estados Unidos. 
derrota de Allende e estavam recebendo uma recompensa merecida por seu trabalho. ${ }^{47}$

Como aconteceu no caso das mulheres brasileiras pró-militares, as mulheres chilenas anticomunistas falaram diretamente ao público norteamericano sobre o seu apoio ao regime militar e o seu papel na derrubada do governo eleito. No entanto, em 1973, a oposição generalizada nos EUA à Guerra do Vietnã e as notícias da invasão republicana da sede do Partido Democrata, em Watergate, criaram uma profunda mudança nas atitudes internas. A opinião pública nos Estados Unidos era muito mais crítica em relação à política externa dos EUA, em geral, e, particularmente, ao papel desempenhado pelo governo dos EUA na derrubada de Allende e no estabelecimento da ditadura militar no Chile. Além disso, os membros do Congresso dos EUA (como Edward Kennedy) não apenas condenaram o golpe, um movimento de solidariedade vibrante emergente que desafiava as interpretações conservadoras do governo de Allende, como também censuraram fortemente o papel dos EUA no golpe, manifestaram oposição às políticas repressoras da ditadura e acolheram os refugiados políticos chilenos nos Estados Unidos. ${ }^{48}$ Cada vez mais, os testemunhos das mulheres anti-Pinochet eram ouvidos e as vozes das anti-Allende e pró-militares eram silenciadas e confinadas, principalmente, às forças conservadoras nos Estados Unidos. Uma exceção ocorreu em Madison, Wisconsin, (de todos os lugares!), que realizou um simpósio de dois dias sobre o Chile, em outubro de 1974. A palestrante do evento foi Carmen Puelma, uma jornalista chilena que tinha escrito artigos contundentes contra o governo Allende e em apoio às mulheres anticomunistas que se opunham a ele. Após o golpe, ela serviu como adida cultural e de imprensa na embaixada do Chile em Washington, D.C. Quando perguntada sobre os presos políticos no Chile, ela comentou: "Eu não falo mais sobre os números, porque estou cansada disso". Ela ficava muito mais confortável falando sobre as mulheres que se opunham a Allende. Puelma observou que elas tinham protagonizado uma série de "marchas de frigideiras e panelas" e que "um número incrível' de mulheres protestaram contra as políticas econômicas de Allende". Além disso, ela atribuiu a "consciência política elevada das mulheres ao fato de que estavam 'nas ruas quase 24 horas por dia', procurando os bens que Allende tornou quase impossível obter" ${ }^{49}$

No entanto, alguns artigos em favor das mulheres anticomunistas e da ditadura militar apareceram na mídia dos EUA. Eda Bolla e seu marido, um executivo aposentado da petrolífera Shell, passaram três meses no Chile,

47 PADILLA, Charles E. They led fight against marxism. Salinas Journal, Kansas, 03/10/1974. For similar articles see, Spunky chilean women honored: heart of "machismo" country. The Daily Review, Haywood, 26/09/1974.

48 Ver POWER, Margaret. The U.S. movement in solidarity with Chile in the 1970s. Latin American Perspectives, v.6, n.6, 11/2009.

49 SWORD, Lew. Chile's problem: a "human" question. Daily News Record, 18/10/1974. 
em 1980. Em uma entrevista, no Alton Telegraph, da cidade natal de Phyllis Schlafly, Bolla apontou que as mulheres, no Chile, não precisavam da Emenda dos Direitos Iguais (ERA) porque "De todas as mulheres do mundo, elas são as mais emancipadas que você pode encontrar". Ela apoiava a ditadura militar do General Augusto Pinochet, que então governava o Chile, e atribuía grande parte do sucesso do golpe "a um grupo de mulheres jornalistas que publicaram panfletos e cartazes e iniciaram as demonstrações." Essas mulheres "fizeram o povo de Santiago bater nas panelas vazias por 30 minutos," todo dia, para sinalizar sua antipatia ao governo de Allende. Por causa delas "o governo comunista [sic] sabia que tinha acabado". ${ }^{50}$

Como mencionado acima, uma figura importante da direita nos EUA, que usou como exemplo as mulheres brasileiras e chilenas anticomunistas, foi Phyllis Schlafly. Em seu estudo sobre Schlafly, Donald Critchlow argumentou que ela foi uma líder poderosa e eficaz da direita republicana do pós-guerra, por causa de "sua habilidade em traduzir ideias conservadoras de ativistas do povo e motivá-los a alcançar seus objetivos políticos". ${ }^{51}$ Um método central que ela empregou para fazer isso eram os grupos de estudo. Num email enviado a mim, em 2009, Schlafly escreveu que, em 1958, ou 1959, "Desenvolvi um programa de estudo de 10 sessões, cada uma baseada em um relatório ou audiência do Congresso sobre o comunismo. Eu fiz uma releitura do programa para três organizações às quais eu pertencia: a Cardinal Mindszenty Foundation (católica, anticomunista), a llinois Federation of Republican Women (Federação das Mulheres Republicanas de Illinois) e a Daughters of the American Revolution (Filhas da Revolução Americana). Em um dado momento, nos gabamos de que tínhamos 5.000 Grupos de Estudo locais". ${ }^{2}$ Os Grupos de Estudo, que incluíam homens e mulheres, consistiam em dez sessões em que os participantes liam documentos publicados pelo Congresso dos EUA ou da Cardinal Mindszenty Foundation. ${ }^{53}$ De acordo com Schlafly, "Eu divulguei informações sobre essas mulheres [brasileiras e chilenas] para levar os americanos a acreditarem que poderíamos ser bem sucedidos. As pessoas que participaram dos grupos de estudo têm conhecido e admirado as mulheres da América do Sul e têm olhado para elas como incentivo". ${ }^{54}$

Phyllis Schlafly também escreveu sobre essas mulheres em O Relatório de Phyllis Schlafly. Em 1977, quando o repúdio mundial ao regime Pinochet

50 HOOVER, Dali. In Santiago Chile equal rights is a past issue for educated women. Alton Telegraph, 05/05/1980.

51 CRITCHLOW, Donald T. Phyllis schlafly and grassroots conservatism, p.6.

52 Phyllis Schlafly, personal communication, email, October 27, 2009. Em 1958 Phyllis Schlafly, seu marido Fred e sua filha Eleanor criaram a Cardinal Mindszenty Foundation, "nomeada após um padre húngaro ser preso por educar os americanos católicos sobre a perseguição que os padres e os cristãos sofriam nos países comunistas". Ver CRITCHLOW, Donald T. The Conservative ascendancy: how the gop right made political history. Cambridge: Harvard University Press, 2007, p.36.

53 Cardinal Mindszenty Foundation. The Cardinal Mindszenty Foundation invites you to combat communism with knowledge and facts. 1973.

54 Phyllis Schlafly, comunicação pessoal, email, 22 outubro 2009. 
era generalizado, Schlafly elogiou o sucesso do governo militar na troca do preso, líder do partido comunista do Chile, Luis Corvalán, pelo dissidente Vladimir Bukovsky, da União Soviética. No mesmo artigo, ela criticou o governo Allende como um "desastre", elogiou o regime militar por pilotar a "recuperação" do Chile e exaltou as "mulheres que iniciaram a derrubada de Allende". "Em 03 dezembro de 1973, [a marcha ocorreu a 01 de dezembro de 1971], elas protagonizaram uma demonstração impressionante, chamada de Marcha das Panelas Vazias. Milhares de mulheres marcharam pelas ruas de Santiago batendo com colheres em suas panelas e frigideiras vazias". ${ }^{55}$

\section{Conclusão}

A fim de analisar a influência dessas mulheres sobre as pessoas nos Estados Unidos, mudei minha atenção dos jornais das grandes cidades, como automaticamente eu fazia no passado, para as dezenas de jornais lidos pelas pessoas fora dos grandes centros metropolitanos. Examinei o que liam aqueles que viviam nas pequenas cidades, municípios e áreas rurais, publicações que havia anteriormente ignorado ou dispensado. Admito fiquei surpresa ao descobrir a ampla cobertura sobre os conservadores brasileiros e chilenos nesses jornais, o que me fez perceber o quão limitada havia sido minha pesquisa anterior.

Além de explorar uma nova gama de fontes, este artigo vai além da ideia de que os Estados Unidos desempenharam o único papel na luta anticomunista nas Américas. Em vez disso, ele mostra que a atividade e o pensamento anticomunista entre as mulheres nas Américas também viajou do Sul para o Norte, não apenas dos Estados Unidos para a América Latina, como geralmente se supõe. As mulheres brasileiras foram pioneiras nesse caminho por meio de sua mobilização contra a presidência reformista de João Goulart. Elas ofereceram às mulheres anticomunistas, em todo o continente, o exemplo inspirador de mulheres se organizando com sucesso para livrar seu país de um presidente democraticamente eleito e apoiar a instalação de uma ditadura militar repressiva. As mulheres chilenas, que se opuseram a Allende, basearam-se no exemplo das mulheres brasileiras e em sua própria história de atividade anticomunista, para forjar um movimento de mulheres conservadoras que apelava às Forças Armadas, com o intuito de derrubar o governo democraticamente eleito e impor uma ditadura militar em seu país.

O trabalho e os sucessos dessas mulheres foram publicados nos Estados Unidos através dos escritos de jornalistas norte-americanos residentes na América do Sul, de colunistas baseados nos EUA e de organizadores

55 The Phyllis Schlafly Report, Alton, v.10, n.10, Section 1, p.4. 
conservadores, como Phyllis Schlafly. Além disso, as mulheres conservadoras brasileiras e chilenas falaram diretamente com as pessoas nos Estados Unidos através, no primeiro caso, da viagem patrocinada pelo Departamento de Estado, dos EUA, ou, no segundo caso, como parte do esforço do governo militar chileno para combater os protestos lançados contra ele, em todo o mundo, por sua violação dos direitos humanos.

Este artigo mostra que os discursos e as identidades nacionalistas, que definem as direitas no Brasil, no Chile e nos Estados Unidos (e em outros lugares), não impedem a adoção simultânea de influências, contatos e recursos transnacionalistas. Em vez de analisar a direita como imersa exclusivamente em seu contexto nacional, este artigo busca incentivar outros estudiosos a examiná-la em relação a e como parte das correntes transnacionais, das quais ela tira ideias e encorajamento. Esta abordagem, acredito, nos permite obter uma compreensão mais profunda dos múltiplos métodos, táticas diversas e estratégias variadas que a direita emprega para organizar, muitas vezes com sucesso, a implementação de sua agenda conservadora e sua ascensão ao poder. 